Association for Information Systems AIS Electronic Library (AISeL)

December 2002

\title{
PARTICIPANTS EXPECTATIONS AND THE SUCCESS OF KNOWLEDGE NETWORKING IN THE PUBLIC SECTOR
}

Jing Zhang

State University of New York at Albany

Anthony Cresswell

State University of New York at Albany

Fiona Thompson

State University of New York at Albany

Follow this and additional works at: http://aisel.aisnet.org/amcis2002

\section{Recommended Citation}

Zhang, Jing; Cresswell, Anthony; and Thompson, Fiona, "PARTICIPANTS EXPECTATIONS AND THE SUCCESS OF KNOWLEDGE NETWORKING IN THE PUBLIC SECTOR" (2002). AMCIS 2002 Proceedings. 88.

http://aisel.aisnet.org/amcis2002/88 


\title{
PARTICIPANTS' Expectations AND THE SUCCESS OF KNOWLedge Networking in The PUblic SeCtor
}

\author{
Jing Zhang, Anthony M. Cresswell, and Fiona Thompson \\ Center for Technology in Government \\ State University of New York at Albany \\ jzhang@ctg.albany.edu tcresswell@ctg.albany.edu \\ fthompso@ctg.albany.edu
}

\begin{abstract}
This paper reports a study of how participants' expectations of interorganizational knowledge sharing are related to the success of information technology projects that require such sharing. Survey data was collected from 478 participants in the six cases in New York State. The study identified four dimensions of participants' expectations of knowledge sharing. They are benefits in providing more effective services, organizational barriers, technological incompatibility, and legal and policy constraints. Furthermore, we find that the participants' expectations regarding organizational barriers are associated with success of knowledge networking. The less positive participants' expectations are about the inter-organizational structure and implementation processes, the less likely their efforts succeed.
\end{abstract}

Keywords: Information sharing, knowledge networking, public sector, collaboration, expectations

\section{Introduction}

Knowledge sharing across the boundaries of government agencies, levels of government, and public, non-profit, and private sector has become an essential element for many applications of electronic government. It has the potential to develop integrative applications, share resources, adapt to new environments, and enhance organizational learning ( Zucker et al. 1995; Bouty 2000). However, many existing organizational, political, and technical factors also posit serious barriers to achieving these benefits (Dawes 1996). This paper focuses on the expectations of participants with regard to the benefits and barriers of interorganizational knowledge sharing by using survey data collected from six cases in New York State. First, the underlying dimensions of participants' expectations will be identified, followed by an examination of the relationship between the participants' expectations and the success of knowledge networking.

The six cases are based on information technology innovation projects conducted by the Center for Technology in Government (CTG). Each project is initiated by a single New York State agency, with participants from other Sate agencies, local government, non-profit organizations, and private sector companies. The goals and the participating organizations of these projects are described in Table 1.

\section{Theoretical Background}

Several studies have contributed to our understanding of how individuals and participating organizations perceive the promises and the risks of interorganizational knowledge sharing. Dawes (1996) discovered that among a group of technical, organizational, and political benefits and barriers suggested by the literature, six factors could be identified to capture the different types of expectations: the potential for solving domain-level problems, reinforcement of value relationships, enhancement in the level of awareness, threats to program integrity and cost of participation. Similarly, McCaffrey, Faerman, \& Hart (1995) argue that, despite many benefits, true participative systems have difficulties sustaining themselves because barriers are deeply embedded in social, 
economic, and political principles. Mistrust of cooperation with prior adversaries, transaction cost of maintaining collaboration in complex social and political systems, difficulties of engaging deep conflicts, and leadership style favoring control are all overridding barriers to the success of true participative systems. Previous studies not only generate an extensive list of potential gains and losses of knowledge sharing, but also point to the existence of underlying dimensions which can group expectations into conceptual categories.

Table 1. Case Description

\begin{tabular}{|c|c|c|}
\hline $\begin{array}{c}\text { Lead Agency, Sample Size, and } \\
\text { Success Score }\end{array}$ & Participants & Purpose of Partnership \\
\hline $\begin{array}{l}\text { NYS Bureau of Housing Services } \\
\mathrm{n}=21 ; \mathrm{SS}=86\end{array}$ & $\begin{array}{l}\text { Providers of services to the homeless in } \\
\text { NYC and region; New York City's Dept. } \\
\text { of Homeless Services; contiguous } \\
\text { counties' Depts of Social Services; NYS } \\
\text { agencies; private corporations }\end{array}$ & $\begin{array}{l}\text { Develop and implement a Homeless } \\
\text { Information Management System }\end{array}$ \\
\hline $\begin{array}{l}\text { NYS Council on Children and } \\
\text { Families } \\
\mathrm{n}=45 ; \mathrm{SS}=37\end{array}$ & $\begin{array}{l}\text { NYS agencies related to CCF; Cornell } \\
\text { University; local government users of } \\
\text { information on children and families; } \\
\text { Annie E. Casey Foundation }\end{array}$ & $\begin{array}{l}\text { Develop and implement a Kids' } \\
\text { Well-being Indicators Clearinghouse }\end{array}$ \\
\hline $\begin{array}{l}\text { NYC's Dept of Information } \\
\text { Technology and } \\
\text { Telecommunications } \\
\text { n=68; SS }=31\end{array}$ & & $\begin{array}{l}\text { Develop policy for NYC's } \\
\text { acquisition and maintenance of IT }\end{array}$ \\
\hline $\begin{array}{l}\text { NYS's Geographical Information } \\
\text { System (GIS) } \\
n=8 ; \mathrm{SS}=87\end{array}$ & $\begin{array}{l}\text { NYS agencies; local governments; private } \\
\text { corporations }\end{array}$ & $\begin{array}{l}\text { Develop, implement, and maintain a } \\
\text { GIS for NYS }\end{array}$ \\
\hline $\begin{array}{l}\text { NYS Office of Real Property } \\
\text { Services } \\
n=145 ; S S=30\end{array}$ & $\begin{array}{l}\text { Real property assessors across the state; } \\
\text { county real property directors; other town } \\
\text { and county officials }\end{array}$ & $\begin{array}{l}\text { Develop and implement a program } \\
\text { of annual reassessment of properties } \\
\text { across the state }\end{array}$ \\
\hline $\begin{array}{l}\text { NYS Office of the State Comptroller } \\
n=190 ; S S=71\end{array}$ & NYS agencies & $\begin{array}{l}\text { Develop a Central Accounting } \\
\text { System }\end{array}$ \\
\hline
\end{tabular}

These expectations of participants in these projects would potentially influence how they participated as well as the overall progress of the innovations involved. When contemplating an innovation or collaborative activity, the participant's expectations concerning the risks and benefits can influence their attitudes and intended actions about the project (Greve 1998; King 1974). Therefore, the first two research questions are:

Q1. What are the underlying factors of participants' expectations about interorganizational knowledge sharing?

Q2. How is the success of knowledge networking associated with participants' expectations?

How participants view these benefits and barriers may vary because of their previous experience working on such initiatives. Dawes (1996) found higher positive expectations were associated with more recent, intensive, and complex sharing experience. The experience the public mangers had in other information sharing projects may provide them more realistic and comprehensive expectations about the benefits and barriers. The benefits they achieved in the past, in Dawes's case, especially motivate them to pursue the continuing effort in interorganizational collaboration. It is not clear, however, how the lessons learned from the field would change the view of participants on the existing barriers. They could be more aware of the formidableness of the existing barriers or more confident in overcoming them. Hence, we are interested to know:

Q3. How are participants' expectations associated with their prior sharing experience?

To what degree the agencies have been cooperative in the past may also influence the respondent's expectations about the benefits and barriers. It is found that difficulties exist in cooperating with agencies that have an adversarial work history (McCaffrey et al. 1995). The contending relationship in the past affects participants' trust on the partners in the network (Zand 1972), which in turn may lower their expectations about the results or benefits of knowledge networking. This suggests the third research question: 
Q4. How are participants' expectations associated with their work history with other participating organizations?

In addition, participants' previous various level of engagement in knowledge sharing and work history with other participants not only shaped their expectations, but also directly relate to the success of knowledge networking projects. More experience and better prepared participants have more understanding about the situation and the partners, and therefore, are able to approach them with modified and proper strategies. Hence, the fourth and fifth questions are:

Q5. How is the success of knowledge networking associated with participants' prior sharing experience?

Q6. How is the success of knowledge networking associated with participants' work history?

Moreover, there is considerable evidence that individual characteristics, such as age and gender, could have an impact on the users' computer literacy, and general attitude toward computing (Agarwal \& Prasad 1999; Venkatesh \& Morris 2000). Consequently, their general attitude and familiarity of the technology could influence their attitude toward such projects that have a strong element of using new technology. Therefore, in this study, the age and gender will be controlled variables. Summarizing the findings from previous study, a path diagram (see Figure 1) is developed to display the relationship between the success of knowledge networking, participants' expectations, prior experience, and individual characteristics.

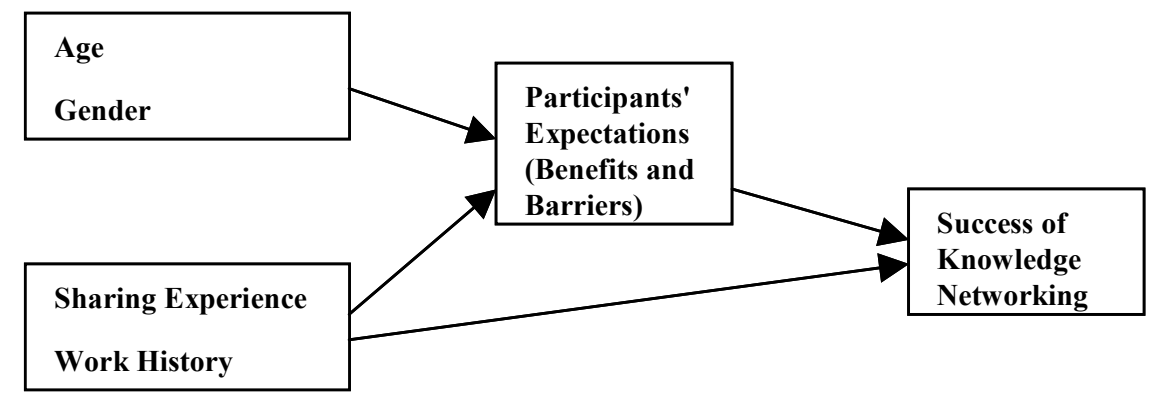
Figure 1. Model Relating Success of Knowledge Networking, Participants' Expectations,
and Participants' Experiences and Characteristics

\section{Method}

This study uses survey data collected by the Center for Technology in Government to study individuals expectations about interorganizational information sharing in the public sector during 1999-2000. The survey is part of a longitudinal multi-method study aimed to develop a comprehensive understanding about factors related to success of knowledge networking. This survey is the first of three surveys planned to be administered over 1999-2002. The initial survey was conducted to measure the initial expectations of the participants involved in order to better understand the relationship between participants' expectations and the outcomes of knowledge networking. The survey was administrated to 478 participants in the six projects involved in inter-agency knowledge sharing. Since the survey was administrated on-site, a 100\% return rate was achieved. The unit of analysis for this study is the individual participants.

Participants' expectations are measured by a Likert scale responses to 41 items (13 potential benefits and 28 potential barriers). The list of items is generated based on key studies (McCaffrey et al., 1995; Dawes, 1996; Dawes, Pardo, Connelly, Green, \& McInerney 1997; Landsbergen \& Wolken 1998). The respondents were asked to indicate to what extent they personally expected each of the 13 items on potential benefits would be achieved by this project within the next 2-3 years; the expectation range was from "not at all likely to be achieve" (coded as 1) to "very likely to be achieved" (coded as 7). Asked to what extent the respondent personally expected each of the 28 items would be a barrier to success in this project, the choice range was from "not a barrier" (coded as 1) to "a severe barrier" (coded as 7). To measure their Prior experience of involvement in planning and designing information sharing programs or projects, the respondents were asked to indicate whether this was the first experience, the second experience, or had they worked on at least two other projects. The survey includes one question asking the respondent to describe the work history among the organizations involved in the project by choosing from: usually cooperative, sometimes cooperative and sometimes adversarial, usually adversarial, not working long enough to know the pattern, and don't know. 
Individual Characteristics as part of the demographic information of participants as individual professionals, such as gender and age, were also collected. Knowledge Networking Success is based on the judgment by a panel consisting of researchers and project managers/facilitators who were intimately involved in each of the six cases. The criteria of the judgment focused not as much on the achievement of formal programmatic goals as on the dynamics of interorganizational collaboration and knowledge sharing. Each case was score with regard to the degree of knowledge and information sharing, collaboration, service innovation, and improved business opportunity and visibility. The resulting scores are indicated in Table 1.

\section{Results}

Overall, all the variables have the maximum value of 7 and the minimal value of 1 . There are missing data on 276 responses (including the "don't know" response). Since there is not systematic missing data, the factor analysis and regression analysis exclude cases with missing values pair wise.

On average, the respondents have a positive expectation that the listed benefits will be achieved (the average score for all of the benefit items are higher than 4). They are also cautious about the impacts of the barriers. Only the last two items, lack of respect for each organization's needs and ability and misinterpretation/misuse of shared information, achieved the mean scores lower than 4 . The rest of the items of barriers were viewed in average as a substantial barrier by the respondents.

A factor analysis was performed using principal component extraction and varimax rotation techniques to detect common factors among the expectations. The analysis results strongly indicate the existence of four common factors, as shown in Table 2. The variables with high loadings (over .50) on factor 1 include all the variables that represent benefit expectations in the survey. Variables representing the barriers have high loadings on one or another of the remaining three factors. The examination of the variables with high loadings on the other factors (in almost all cases .50 or above) reveals strong consistency as well. The factors can be conceptualized as shown below:

- $\quad$ Factor 1: benefits (e.g., more effective and better coordinated services);

- Factor 2: organizational barriers (e.g., the conflicting organizational priorities and implementation difficulties)

- $\quad$ Factor 3: technological incompatibility (e.g., lack of tools and skills, communication networks and standard);

- Factor 4: legislative and policy constraints (e.g., .restrictive laws and regulation, and confidentiality regulation).

For the subsequent analyses exploring influences on project success, the factor scores from these first four components of the principal components analysis were used to represent the underlying factors shown above. The correlations among the variables used in this second analysis are shown in Table 3. As work history is measured by categorical variable, it is transformed into three dummy variables (usually cooperative, sometimes cooperative, and don't know as comparing to usually adversarial) to account for the differences of work history and its correlation with other variables.

To test the model in Figure 1, a set of regressions were conducted with the project success as the independent variables. The results are presented in Table 4. Participant prior sharing experience, work history, age, and gender account for only 4.6 percent of the variance in the success variable, and the overall models does not yield a significant result $(p>0.1)$. When the set of variables measuring participants' expectations are added in equation 2 , the model explained another 6.4 percent of the variance in success $(\mathrm{p}<0.01)$.

In the second equation, the expectation of organizational barriers is significantly related to the success of knowledge networking $(\mathrm{p}<0.01)$. It appears that the projects are less successful in situations where the participants expect organizational barriers to be more serious constraints to the knowledge sharing. In addition, age also appear to be related to the success of knowledge networking $(\mathrm{p}<0.05)$. The successful cases are associated with a younger population of participants. These results do not, however, indicate whether it is the expectations of the participants that influence the project's success directly or whether the participants are able to identify projects where success is inherently more difficult to obtain. 
Table 2. Rotated Components Matrix ${ }^{\mathrm{a}}$

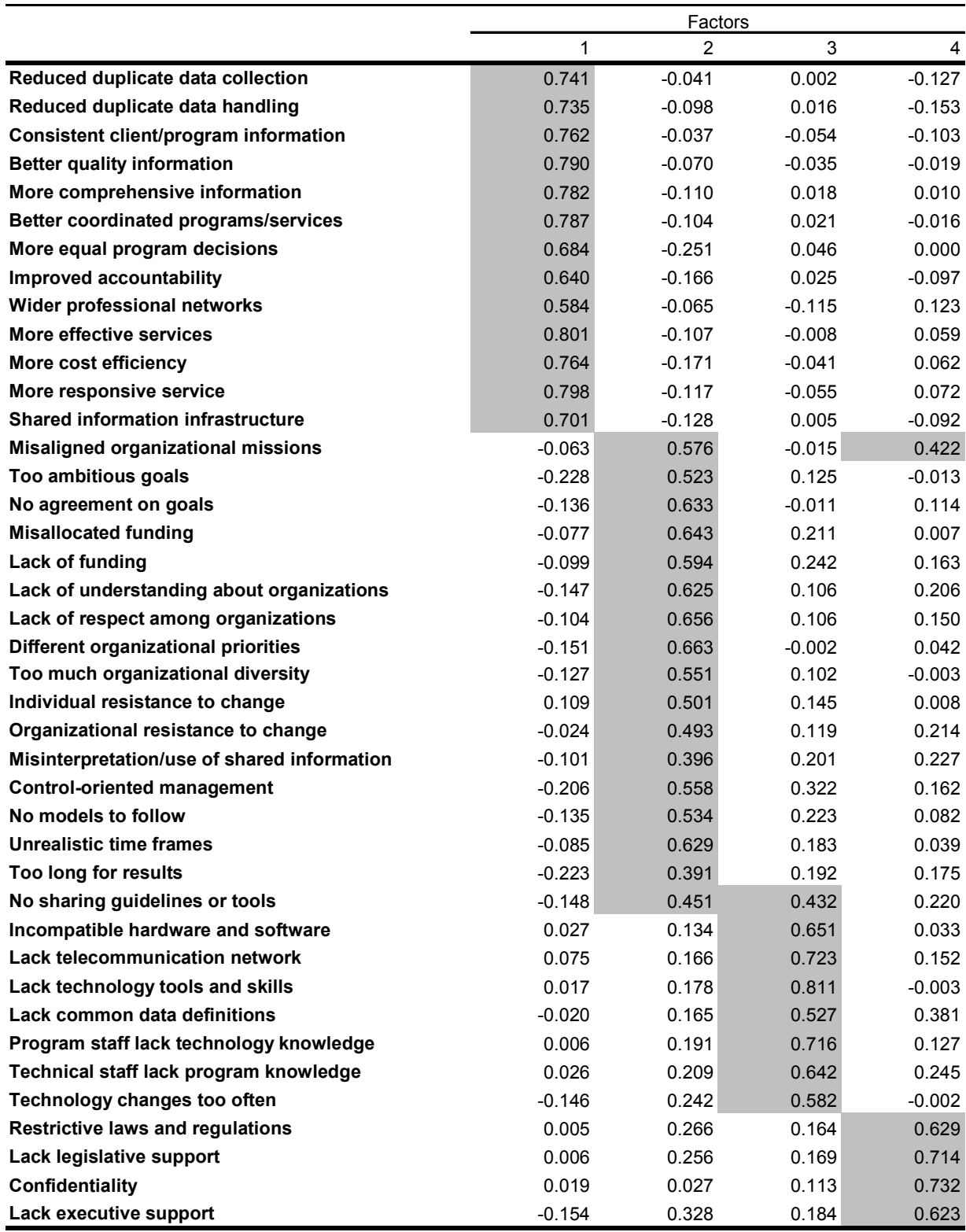

a. Extraction Method: Principal Component Analysis. Extraction is limited to 4 factors.

Rotation Method: Varimax with Kaiser Normalization.

Rotation converged in 6 iterations. Total variance explained is $48.99 \%$. 
Table 3. Correlation Structure

\begin{tabular}{|c|c|c|c|c|c|c|c|c|c|c|}
\hline & $\begin{array}{l}\text { Success } \\
\text { Score }\end{array}$ & 1 & 2 & 3 & 4 & 5 & 6 & 7 & 8 & 9 \\
\hline $\begin{array}{l}\text { 1. REGR factor score } 1 \\
\text { (Benefits) }\end{array}$ & $0.138^{*}$ & & & & & & & & & \\
\hline $\begin{array}{l}\text { 2. REGR factor score } 2 \\
\text { (Organizational Barriers) }\end{array}$ & $-0.251^{\star *}$ & -0.068 & & & & & & & & \\
\hline $\begin{array}{l}\text { 3. REGR factor score } 3 \\
\text { (Technology Incompetibility) }\end{array}$ & -0.050 & 0.070 & -0.057 & & & & & & & \\
\hline $\begin{array}{l}\text { 4. REGR factor score } 4 \text { (Legal } \\
\text { and Policy Contraints) }\end{array}$ & 0.051 & 0.021 & 0.033 & -0.001 & & & & & & \\
\hline 5. Prior Sharing Experience & -0.043 & -0.091 & 0.085 & -0.039 & 0.123 & & & & & \\
\hline 8. Don't Know & -0.001 & 0.005 & -0.051 & 0.056 & -0.033 & $-0.126^{* *}$ & $-0.474^{* *}$ & $-0.363^{* *}$ & & \\
\hline 9. Age & $-0.159^{* *}$ & 0.013 & 0.036 & 0.019 & -0.035 & $0.117^{\star}$ & $0.137^{\star *}$ & -0.082 & -0.067 & \\
\hline 10. Gender & 0.062 & -0.093 & $-0.150^{*}$ & 0.108 & 0.004 & $-0.152^{* *}$ & -0.025 & -0.056 & $0.124^{\star *}$ & $-0.125^{\star *}$ \\
\hline
\end{tabular}

Table 4. Hierarchical Regression Models with the Success of Knowledge Networking as Dependent Variable

\begin{tabular}{lrr}
\hline & Models & \\
\cline { 2 - 3 } Independent Variables & $56.124^{* \star *}$ & 2 \\
\hline (Constant) & $-4.052^{*}$ & $57.779^{* \star *}$ \\
Age & 0.111 & $-3.716^{*}$ \\
Priorn Sharing Experience & 4.445 & 0.362 \\
Gender & 5.675 & 4.000 \\
Usually Cooperative & 0.472 & 2.053 \\
Sometimes Cooperative & 4.122 & -0.987 \\
Don't Know & & 0.933 \\
Benefits & & 2.472 \\
Organizational Barriers & & $-4.637^{* *}$ \\
Technology Incompetibility & & -1.361 \\
Legal and Policy Constraints & 0.045 & 1.249 \\
\hline R Square & 0.018 & 0.109 \\
Adjusted R Square & & 0.066 \\
\hline & & \\
Hierarchical F test & & 0.064 \\
\hline R Square Change & & 3.704 \\
F & & 4,207 \\
d.f. & & 0.006 \\
\hline $\mathrm{p}$ & & \\
\hline & & \\
${ }^{*} p<.05,{ }^{* *} p<.01,{ }^{* * *} p<.001$ & &
\end{tabular}




\section{Discussion}

In general, the respondents held optimistic expectations on the benefits of knowledge sharing. They tend to expect that those benefits are likely to be achieved. At the mean time, they are also very much aware of the potential barriers for achieving those benefits. It is reasonable to expect that those public and nonprofit managers are motivated to achieve the expected benefits and will be approaching these benefits cautiously with the knowledge about the policy, organizational and technological barriers that they have to deal with in initiating a program involving sharing information and knowledge.

Participant expectations in regard to the organizational barriers are negatively associated with the success of knowledge networking. The projects that have higher score on the importance of these organizational barriers were less successful. One explanation is related to how the perception is constructed in relation to the organizational realities. Participants' perception may very well reflect the difficulties deeply embedded in organizational structures and processes. As O'Dell and Grayson (1998) pointed out, the actual process of sharing is often thwarted by a variety of obstacles resulting from structural conflicts, managerial practices, and evaluation and incentive systems that discourage sharing. Failing to address those embedded barriers will only lead to disappointment and failure.

Beyond this theoretical explanation, a much more in-depth understanding of the relationship between organizational barriers and the success of knowledge sharing can be arrived at by analyzing the observational and interview data collected in the larger research study. For instance, the Office of Real Property Services (ORPS) project was embedded in historically antagonistic relationships among those who had to work together for the project to succeed. Conversely, the NYS's Geographical Information System (GIS) project was initiated by a small group of enthusiasts from a range of state agencies who worked together in this new area to develop a cross-agency information system from scratch. In this case there was no institutional conflict to challenge the success of their project.

Furthermore, perceptions can also be a significant factor for success in their own right. The structural obstacles participants perceive may limit the ways that they engage themselves in collaborative work. They may be less inspired by or committed to the changes, and be more conservative in taking risks, which in turn affect the outcomes of knowledge networking. Their expectations can become a self-fulfilling prophecy that perpetuates those obstacles (Kanter 1977). For instance, when the Bureau of Housing Services (BHS) proposed data sharing for a homeless information system, the perception among service providers was that this would threaten their clients' confidentiality. In order to overcome this problematic perception, BHS had to provide a signed statement from the head of the agency quoting the state law by which this and other state agencies were required to abide.

Surprisingly, the sharing experience the respondents had in the past does not account for the difference in the success. A possible explanation might have to do with a steep learning curve for technology changes. Many systems are still in the stage of trials and errors. As Schön observed, the situation confronting public professionals is characteristics by complexity, instability, uncertainty, and uniqueness (Schön 1982). The complexity and uniqueness of the technology and process changes involved makes success a such challenging task that even experience participants have difficulties to grasp.

As the result indicated, the work history, as well as participants' expectations on technology incompatibility and legal and policy constraints are not significantly related to the success of knowledge networking. Partly, this result shows that the six cases are situated in similar technological and policy environment. More importantly, it demonstrate the demands for studies with qualitative and feedback dynamic approaches. The quantitative analysis should be supplemented by the qualitative data derived from document analysis, observations, and interviews to comprehend the dynamics of the interplay between work history, collaboration, organizational, technological, and political environment. This line of research is being actively pursued by the Center (e.g, Cresswell et al., 2002). This study points to the limitation of only using quantitative approach in studying a relatively small number of cases.

Although this study achieved a relatively large sample, the participants were not randomly selected. The available population from 7 projects was the subject of study. Those projects are self-selected. They approached the Center for Technology in Government because of their special interest and needs in the innovation projects. This could indicate an exceptionally high preference for information sharing activities or innovation. The attitudes of the participants may not represent those in the whole public sector in New York State. However, the results from the survey, especially the factors of potential risks and barriers, offer valuable guidance for those who are planning such projects. 


\section{Conclusion and Recommendations}

This study identifies four dimensions of participants' expectations of knowledge sharing. They are benefit in providing more effective services, organizational barriers, technological incompatibility, and legal and policy constraints. Furthermore, we find the success of knowledge networking is significantly associated with participants' expectations regarding the organizational barriers to project success. The less positive they are about the inter-organizational structure and implementation processes, the less likely their efforts succeed.

These findings have several implications for both the conduct of collaborative projects and further research on this topic. First of all, researchers, policy makers, and practitioners should pay substantial attention the existing inter-organizational structures and processes with regard to their impact on the interorganizational sharing activities. It should be recognized that failing to address those discouraging structural conflicts and managerial practices can lead to expensive failures. In addition, the perception of professionals in public sector can be guided or influenced in more positive directions by a process called double-loop learning (Argyris \& Schön 1996), which prescribes organizational learning as processes to go beyond of simply detecting and acting on the gaps between strategies and expectations, but to surface and modify the value and assumptions governing the establishment of expectations. In so doing, the double-loop feedback can be very instrumental in such significant changes as what the participants in the above innovating projects need to encounter.

This study also points to the need for studies combining the strength of qualitative and quantitative approach. Case studies methods can provide better insights into the dynamics of these projects, insights that are not likely to be revealed by crosssectional survey data. The richness of the connection between different variables, the existence of interactive feedback loop, and the effects of external events can not be captured without the supplementary results from qualitative data analysis and perspectives that draw on concepts from system dynamics.

\section{References}

Agarwal, R., and Prasad, J. "Are Individual Differences Germane to the Acceptance of New Information Technologies," Decision Sciences (30:2), 1999, pp. 361-391.

Argyris, C., and Schön, D. A. Organizational Learning II: Theory, Method, and Practice, Addison-Wesley Publishing Company, 1996.

Bouty, I. "Interpersonal and Interaction Influences on Informal Resource Exchanges between R\&D Researchers across Organizational Boundaries," Academy of Management Journal (43:1), 2000, pp. 50-65.

Cresswell, A. M., Pardon, T. A., Thompson, F., Canestraro, D. S., Cook, M., Black, L. J., Luna, L. F., Martinez, I. J., Andersen, D. F. "Modeling intergovernmental collaboration: A system dynamics approach," Paper presented at the Hawaiian International Conference on System Sciences-35, Hawaii., 2002.

Dawes, S. "Interagency Information Sharing: Expected Benefits, Manageable Risks," Journal of Policy Analysis and Management (15;3), 1996, pp. 377-394.

Greve, H. R. "Performance, Aspirations, and Risky Organizational Change," Administrative Science Quarterly (43:1), 1998, pp. 58-87.

Kanter, R. M. Men and Women of the Corporation, BasicBook, 1977.

McCaffrey, D. P., Faerman, S. R., and Hart, D. W. The Appeal and Difficulties of Participative Systems. Organization Science (6:6), 1995, pp. 603-627.

O'Dell, C., and Grayson, C. J., Jr. If Only We Knew What We Know, New York: The Free Press, 1998.

Schön, D. A. The Reflective Practitioner: How Professionals Think in Action, Basic Book, Inc, 1982.

Venkatesh, V., and Morris, M. G. "Why don't Men ever Stop to Ask for Directions? Gender, Social Influence, and Their Role in Technology Acceptance and usage behavior," MIS Quarterly (24:1), 2000, pp. 115-139.

Zucker, L. G., Darby, M. R., Brewer, M. B., and Peng, Y. "Collaboration Structure and Information Dilemmas in Biotechnology: Organizational Boundaries as Trust Production," In R. M. Kramer and T. R. Tyler (Eds.), Trust in organizations: Frontiers of theory and research, Thousand Oaks, CA: Sage, 1995. 